\title{
Rubidium extraction using an organic polymer encapsulated potassium copper hexacyanoferrate sorbent
}

\author{
Gayathri Naidu ${ }^{\mathrm{a}}$, Paripurnanda Loganathan ${ }^{\mathrm{a}}$, Sanghyung Jeong ${ }^{\mathrm{b}}$, Md.Abu Hasan Johir ${ }^{\mathrm{a}}$, Vu Hien \\ Phuong To ${ }^{a}$, Jaya Kandasamya , Saravanamuthu Vigneswaran ${ }^{\mathrm{a}, *}$
}

\footnotetext{
${ }^{a}$ Faculty of Engineering, University of Technology Sydney (UTS), P.O. Box 123, Broadway, NSW 2007 Australia,

${ }^{\mathrm{b}}$ King Abdullah University of Science and Technology (KAUST), Water Desalination and Reuse Center (WDRC), Biological and Environmental Science \& Engineering (BESE), Thuwal 23955-6900, Kingdom of Saudi Arabia
}

*Corresponding author: Tel +61-2-9514-2641; Fax +61-2-9514-2633; Email: Saravanamuth.Vigneswaran@uts.edu.au

\section{Abstract}

Sea water reverse osmosis (SWRO) brine contains significant quantity of $\mathrm{Rb}$. As an economically valuable metal, extracting $\mathrm{Rb}$ using a suitable and selective extraction method would be beneficial. An inorganic sorbent, copper based potassium hexacyanoferrate $(\mathrm{KCuFC})$, exhibited high selectivity to extract $\mathrm{Rb}$ compared to potassium hexacyanoferrate consisting of other transition metal combinations such as Ni, Co and Fe. An organic polymer (polyacrylonitrile, PAN) encapsulated KCuFC (KCuFCPAN) achieved a Langmuir maximum Rb sorption capacity of $1.23 \mathrm{mmol} / \mathrm{g}$ at $\mathrm{pH} 7.0 \pm 0.5$. KCuFCPAN showed Rb selectivity over a wide concentration range of co-existing ions and salinity of SWRO brine. High salinity $(0.5-2.5 \mathrm{M} \mathrm{NaCl})$ resulted in $12-30 \%$ sorption capacity reduction. At a molar ratio of $\mathrm{Li}: \mathrm{Rb}(21: 1), \mathrm{Cs}: \mathrm{Rb}(0.001: 1)$ and $\mathrm{Ca}: \mathrm{Rb}(14,700: 1)$ commonly found in SWRO brine, sorption reduction of only $18 \%$ occurred. Nevertheless, at a very high $\mathrm{K}: \mathrm{Rb}$ molar ratio (7700:1), KCuFC-PAN sorption capacity of $\mathrm{Rb}$ reduced significantly by $65-70 \%$. KCuFC-PAN was well suited for column operation. In a fixed-bed KCuFC-PAN column (influent concentration $0.06 \mathrm{mmol} \mathrm{Rb} / \mathrm{L}$, flow velocity 
$242 \mathrm{~m} / \mathrm{h}$ ), two sorption/desorption cycles were successfully achieved with a maximum Rb sorption capacity of 1.01 (closely similar to the batch study) and $0.85 \mathrm{mmol} / \mathrm{g}$ in the first and second cycles, respectively. Around $95 \%$ of $\mathrm{Rb}$ was desorbed from the column with $0.2 \mathrm{M} \mathrm{KCl}$. Resorcinol formaldehyde $(\mathrm{RF})$ resin showed promising results of separating $\mathrm{Rb}$ from $\mathrm{K} / \mathrm{Rb}$ mixed solution in effluents from a fixed-bed column, and a subsequent sequential acid desorption, producing $68 \%$ purified $\mathrm{Rb}$.

Keywords potassium copper hexacyanoferrate, purification, reverse osmosis brine, rubidium, seawater, sorption.

\section{Introduction}

Sea water reverse osmosis (SWRO) brine contains trace alkali metals that are economically

valuable. Presently, much attention has been focused on rubidium $(\mathrm{Rb})$ recovery in view of its high economic potential at 7857 Euros/kg in comparison to other metals such as cesium (Cs), lithium (Li), germanium and indium [1]. $\mathrm{Rb}$ is used in specific fields such as fibre optic telecommunication and laser technology [2]. In SWRO brine, Rb is present at low concentrations $(0.19$ to $0.21 \mathrm{mg} / \mathrm{L})$ with other dominant ions such as sodium $(\mathrm{Na})$, potassium $(\mathrm{K})$, calcium $(\mathrm{Ca})$, magnesium $(\mathrm{Mg})$ and $\mathrm{Li}$ in highly saline condition $[1,3]$.

Inorganic ion-exchange sorbents are widely used in the extraction of metals found in low concentration due to its high selective sorption capacity in mixed metals solutions [4]. In this context, potassium metal hexacyanoferrate $(\mathrm{K}(\mathrm{M}) \mathrm{FC}$ (M refers to transition metals such as cobalt $(\mathrm{Co})$, copper $(\mathrm{Cu})$, iron $(\mathrm{Fe})$, zinc $(\mathrm{Zn})$ and nickel $(\mathrm{Ni}))$, is known for its versatile applications for trace alkali metal extraction under high saline conditions [1,5]. Considerable effort has been made on the development 
of $\mathrm{K}(\mathrm{M}) \mathrm{FC}$ especially for radioactive Cs removal from nuclear waste solutions [6]. A variety of metal combinations are used to make $\mathrm{K}(\mathrm{M}) \mathrm{FC}$ sorbent including $\mathrm{Co}, \mathrm{Ni}, \mathrm{Fe}$ (Prussian Blue), $\mathrm{Zn}$ and $\mathrm{Cu}$ $[7,8]$. Potassium cobalt hexacyanoferrate $(\mathrm{KCoFC})$ is commercially available due to its high selectivity for radioactive Cs removal [6,9]. $\mathrm{K}(\mathrm{M}) \mathrm{FC}$ with other metal based combinations such as $\mathrm{Cu}(\mathrm{KCuFC})$, $\mathrm{Zn}(\mathrm{KZnFC}), \mathrm{Fe}(\mathrm{KFeFC})$ and $\mathrm{Ni}(\mathrm{KNiFC})$ have also shown satisfactory results in Cs extraction from nuclear waste [7-9]. $\mathrm{K}(\mathrm{M}) \mathrm{FC}$ with different metal combinations to increase selective sorption of $\mathrm{Rb}$ has not been compared in a single study so far. This information would be useful in identifying a occurrence of fine-grained powder of microcrystalline natured $\mathrm{K}(\mathrm{M}) \mathrm{FC}$ sorbent resulting in clogging of bed and decrease in filtration rates. One of the approaches to overcome this limitation is to biosorbent polymers and biopolymers [8,10-12]. of $\mathrm{Rb}$ from an encapsulated sorbent. It is worth highlighting that most of the available studies on

Fe and Ni) for Rb sorption, (ii) characterise and evaluate the performance of encapsulated K(M)FCPAN beads for $\mathrm{Rb}$ sorption under high salinity and in the presence of competing metal ions, (iii) test

Furthermore, desorption of the sorbed $\mathrm{Rb}$ is important in determining the degree of recovery $\mathrm{K}(\mathrm{M}) \mathrm{FC}$ were focused on retaining radioactive $\mathrm{Cs}$ on the sorbent for solid disposal. Thus, desorption was not an essential factor in those studies. Some studies have highlighted $\mathrm{Cs}$ and $\mathrm{Rb}$ desorption using $0.5 \mathrm{M}$ (up to $3.0 \mathrm{M}$ ) $\mathrm{KCl}, \mathrm{NH}_{4} \mathrm{Cl}$ and $\mathrm{HNO}_{3}[5,11,13]$. Upon desorption, $\mathrm{Rb}$ would be found mixed with other desorbed ions from $\mathrm{K}(\mathrm{M}) \mathrm{FC}$ and ions derived from the desorbing agent. Thus, subsequent purification process from these unwanted ions is essential to obtain a high quality $\mathrm{Rb}$.

The objectives of this study were to (i) identify a suitable $\mathrm{K}(\mathrm{M}) \mathrm{FC}$ metal combination (Co, $\mathrm{Cu}$, the practical $\mathrm{Rb}$ sorption and desorption performances of $\mathrm{K}(\mathrm{M}) \mathrm{FC}-\mathrm{PAN}$ in a fixed-bed column and the sorbent's regeneration capacity for its reuse, and (iv) purify $\mathrm{Rb}$ from the desorbed solution. 


\section{Material and methods}

\section{$74 \quad 2.1 \quad$ Materials}

\section{$75 \quad 2.1 .1 \quad$ Solutions}

Solutions used for making the sorbents include potassium ferrocyanide trihydrate $77\left(\mathrm{~K}_{4} \mathrm{Fe}(\mathrm{CN})_{6} \cdot 3 \mathrm{H}_{2} \mathrm{O}\right)$, cobalt nitrate hexahydrate $\left(\mathrm{Co}\left(\mathrm{NO}_{3}\right)_{2} \cdot 6 \mathrm{H}_{2} \mathrm{O}\right)$, nickel nitrate hexahydrate $78\left(\mathrm{Ni}\left(\mathrm{NO}_{3}\right)_{2} \cdot 6 \mathrm{H}_{2} \mathrm{O}\right)$, copper nitrate trihydrate $\left(\mathrm{Cu}\left(\mathrm{NO}_{3}\right)_{2} \cdot 3 \mathrm{H}_{2} \mathrm{O}\right)$ and ferric chloride hexahydrate $79\left(\mathrm{FeCl}_{3} \cdot 6 \mathrm{H}_{2} \mathrm{O}\right)$. Stock solutions of $\mathrm{Rb}, \mathrm{Cs}, \mathrm{Li}, \mathrm{K}, \mathrm{Na}$ and $\mathrm{Ca}$ were prepared by dissolving $\mathrm{RbCl}, \mathrm{CsCl}$, $80 \mathrm{LiCl}, \mathrm{KCl}, \mathrm{NaCl}$ and $\mathrm{CaCl}_{2}$, respectively, in deionised (DI) water. The binder materials used for sorbent 81 encapsulation were polyacrylonitrile $(\mathrm{PAN}, \mathrm{MW}=150,000 \mathrm{~g} / \mathrm{mol})$, dimethyl sulfoxide (DMSO, $\left.82\left(\mathrm{CH}_{3}\right)_{2} \mathrm{SO}, 99.9 \%\right)$ and Tween80. All reagents were of analytical grade (Sigma Aldrich) and were used 83 without further purification.

\subsubsection{Sorbent preparation}

\subsubsection{Potassium metal hexacyanoferrate, K(M)FC}

$\mathrm{K}(\mathrm{M}) \mathrm{FC}$ sorbents were prepared by adding one volume of $0.5 \mathrm{M} \mathrm{K}_{4} \mathrm{Fe}(\mathrm{CN})_{6} \cdot 3 \mathrm{H}_{2} \mathrm{O}$ to 1.5 volumes of excess transition metal $(0.5 \mathrm{M} \mathrm{Fe}, \mathrm{Co}, \mathrm{Cu}$, and $\mathrm{Ni})$. This resulted in a metal/Fe molar ratio of 1.5. Similar metal hexacyanoferrate combinations with metal/Fe molar ratios from 1.4 to 1.8 were reported in previous studies [6-9]. Nitrate salts of metals were used for all the metal sorbent mixtures

91 except for Fe (as per the Prussian blue procedure, ferric chloride was used). The solutions were stirred,

92 followed by centrifuging, washing the residue with DI water based on the different metal combinations of Fe [14]; Co [9], $\mathrm{Cu}$ [15]; and $\mathrm{Ni}[16]$. 


\subsubsection{Particle form $K(M) F C$}

Each $\mathrm{K}(\mathrm{M}) \mathrm{FC}$ mixture was dried for $24 \mathrm{~h}$ based on the previous studies $\left(\mathrm{Co}-115^{\circ} \mathrm{C}, \mathrm{Fe}-90^{\circ} \mathrm{C}\right.$,

$97 \mathrm{Ni}-70{ }^{\circ} \mathrm{C}$, and $\left.\mathrm{Cu}-55^{\circ} \mathrm{C}\right)[9,14-16]$. The dried granules were ground to a particle size of $0.25-0.45$ $98 \mathrm{~mm}$. This is referred to as particle form $\mathrm{K}(\mathrm{M}) \mathrm{FC}$.

\subsubsection{Bead form $K(M) F C(K(M) F C-P A N)$}

$\mathrm{K}(\mathrm{M}) \mathrm{FC}-\mathrm{PAN}$ was prepared with $70 \mathrm{wt} \%$ of sorbent loaded on PAN according to the procedure 102

PAN beads were washed three times with DI water and oven dried at $60{ }^{\circ} \mathrm{C}$ for $24 \mathrm{~h}$. The steps involved

107 in the preparation of the K(M)FC-PAN beads are illustrated in Fig. 1.

\subsubsection{Resorcinol formaldehyde polycondensate resin ( $\mathrm{RF}$ resin)}

$\mathrm{RF}$ resin was prepared by polycondensation of formaldehyde with resorcinol. A resorcinol:

111 Samanta et al. [18]. The mixture was oven dried at $100{ }^{\circ} \mathrm{C}$ for $24 \mathrm{~h}$. The dried $\mathrm{RF}$ resin was ground 112 and sieved to $0.25-0.45 \mathrm{~mm}$ particle size. It was then converted to an acid form ( $\mathrm{H}$ form) by using $113 \mathrm{HCl}$, followed by filtration and air drying of the residue. 
$114 \quad 2.2 \quad$ Sorbent characterisation

$115 \quad$ 2.2.1 Mineralisation analysis

116 Samples $(0.05 \mathrm{~g})$ of particle form $\mathrm{K}(\mathrm{M}) \mathrm{FC}$ as well as original and column regenerated $117 \mathrm{~K}(\mathrm{M}) \mathrm{FC}-\mathrm{PAN}$ were decomposed in $1 \mathrm{~mL}$ of concentrated $\mathrm{H}_{2} \mathrm{SO}_{4}(98 \%)$ as per the procedure of Naidu 118 et al. [5]. Concentrations of K, Fe and transition metals in the aqueous samples were measured using 119 Agilent technologies 7700 inductively coupled plasma mass spectrometry (ICP-MS). The procedure 120 was repeated in triplicate. The average results are reported in this study. The deviation between the 121 replicated values was lower than $10 \%$.

\section{$123 \quad 2.2 .2 \mathrm{pH}$ and zeta potential}

The effect of $\mathrm{pH}$ on sorption at equilibrium condition was investigated by suspending $0.005 \mathrm{~g}$ 125 sorbent in a beaker containing $100 \mathrm{~mL}$ of $0.06 \mathrm{mmol} \mathrm{Rb} / \mathrm{L}$ solution with initial solution $\mathrm{pH}$ set in the range of $\mathrm{pH} 3$ to 9 . The beakers were agitated for $12 \mathrm{~h}$ in a flat shaker. The final $\mathrm{pH}$ at equilibrium was 127 recorded, which was reported as $\mathrm{pH}_{\mathrm{eq}}$.

To investigate the zeta potential of the particle form $\mathrm{K}(\mathrm{M}) \mathrm{FC}$ at equilibrium condition, suspensions of $1 \mathrm{~g} / \mathrm{L}$ particle form $\mathrm{K}(\mathrm{M}) \mathrm{FC}$ in $100 \mathrm{~mL}$ DI water (with initial solution $\mathrm{pH}$ set in the range of $\mathrm{pH} 3$ to 9), were agitated for $12 \mathrm{~h}$ in a flat shaker. The final $\mathrm{pH}_{\mathrm{eq}}$ was recorded. The zeta potential was measured by a Zetasizer nano instrument (Nano ZS Zen3600, Malvern, UK) using laser doppler micro-electrophoresis technology that detected the dispersion of $\mathrm{K}(\mathrm{M}) \mathrm{FC}$ particles in solution 133 which was placed in a capillary cell with electrodes. Measurements were done in triplicate (with 134 differences between replicates being less than 5\%). Results of the average value were reported. 
2.2.3 Scanning electron microscopy with energy dispersive X-ray spectroscopy (SEM/EDX) analysis

The surface and cross sectioned sorbent morphology and element contents before and after $\mathrm{Rb}$ sorption were evaluated with scanning electron microscopy (SEM) coupled with energy dispersive Xray spectroscopy (EDX) operated at $15 \mathrm{kV}$ (Zeiss Supra 55VP Field Emission) as in the procedure of 141 Naidu et al. [5]. $10^{\circ}-80^{\circ}$

\subsubsection{X-ray diffraction (XRD) analysis}

XRD patterns were recorded using a Siemens D5000 diffractometer operated with CuKa radiation and a rotating sample stage. The samples (particle form $\mathrm{K}(\mathrm{M}) \mathrm{FC}, \mathrm{K}(\mathrm{M}) \mathrm{FC}-\mathrm{PAN}$ and column regenerated $\mathrm{K}(\mathrm{M}) \mathrm{FC}-\mathrm{PAN}$ ) in powder form were scanned at room temperature in $2 \Theta$ angular range of

\subsection{Sorption experiments}

\subsubsection{Sorption isotherms}

Equilibrium sorption experiments were conducted in a set of glass flasks containing $100 \mathrm{~mL}$ solutions of $0.06 \mathrm{mmol} \mathrm{Rb} / \mathrm{L}$ and different doses of particle form $\mathrm{K}(\mathrm{M}) \mathrm{FC}$ sorbents as well as $\mathrm{K}(\mathrm{M}) \mathrm{FC}$ PAN ranging from 0.03 to $0.50 \mathrm{~g} / \mathrm{L}$. The $\mathrm{pH}$ value of the solutions was maintained at $7.0 \pm 0.5$. The suspensions were agitated for $24 \mathrm{~h}$ to reach the sorption equilibrium. The supernatant solution was analysed for $\mathrm{Rb}$ and $\mathrm{K}$ using contrAA ${ }^{\circledR} 300$ Analytikjena atomic absorbance spectrometry (AAS). The experiments were duplicated ( $\pm 2 \%$ difference) and the average values were taken for data analysis. The $\mathrm{Rb}$ sorption amount at equilibrium, $\mathrm{q}_{\mathrm{e}}(\mathrm{mmol} / \mathrm{g})$, was calculated using Eq. (1): 158

$$
q_{e}=\frac{\left(C_{0}-C_{e}\right) \cdot V}{M}
$$


159 where, $\mathrm{C}_{0}$ and $\mathrm{C}_{\mathrm{e}}$ are the initial and equilibrium concentration of $\mathrm{Rb}$ in the bulk solution (mmol/L), $\mathrm{V}$ 160 is volume of solution (L) and $\mathrm{M}$ is mass of sorbent $(\mathrm{g})$.

161 The sorption data were modelled according to Langmuir and Freundlich isotherms based on 162 the model equations presented in another study [5].

mmol $\mathrm{Rb} / \mathrm{L}$ ) and sorbent dose $0.05 \mathrm{~g} / \mathrm{L}$. The $\mathrm{pH}$ value of the solutions was maintained at $7.0 \pm 0.5$. another study [5].

171 \pm 0.5 . 


\subsubsection{Column experiments}

$$
q_{\text {total }}=\frac{Q}{1000} \int_{t=0}^{t=\text { total }}\left(C_{o}-C_{t}\right) d t
$$

198 Equilibrium uptake, $\mathrm{q}_{\mathrm{e}}(\mathrm{mmol} \mathrm{Rb} / \mathrm{g})$, is defined by Eq. (3) as the total amount of adsorbed $\mathrm{Rb}\left(\mathrm{q}_{\text {total }}\right)$ 199 per $g$ of sorbent $(\mathrm{M})$ at the end of the experiment:

200

$$
q_{e}=\frac{q_{\text {total }}}{M}
$$




\section{$2.4 \quad$ Rb desorption and $\mathrm{K}(\mathrm{M}) \mathrm{FC}-\mathrm{PAN}$ regeneration}

\subsubsection{Batch experiment}

Potassium chloride $(\mathrm{KCl})$ was used to desorb $\mathrm{Rb}$ from $\mathrm{K}(\mathrm{M}) \mathrm{FC}-\mathrm{PAN}$, based on the positive results obtained in our previous study [5]. To determine the suitable $\mathrm{KCl}$ concentration for the regeneration of $\mathrm{K}(\mathrm{M}) \mathrm{FC}-\mathrm{PAN}$, desorption was carried out using different molar concentrations of $\mathrm{KCl}$ from $0.1 \mathrm{M}$ to $0.5 \mathrm{M}$ after saturating $\mathrm{Rb}$ on $\mathrm{K}(\mathrm{M}) \mathrm{FC}-\mathrm{PAN}$ by equilibrating $0.06 \mathrm{mmol} \mathrm{Rb} / \mathrm{L}$ with 0.1 $\mathrm{g} / \mathrm{L}$ of K(M)FC-PAN. The procedure of desorption was similar to that described previously [5].

\subsubsection{Column experiment}

In the column study, upon the complete breakthrough, $\mathrm{K}(\mathrm{M}) \mathrm{FC}-\mathrm{PAN}$ was washed with DI water followed by $\mathrm{KCl}$ (suitable concentration determined from the batch study) at an upward velocity of $6 \mathrm{~m} / \mathrm{h}$. The $\mathrm{Rb}$ concentrations in the desorbed solution were measured periodically. Two cycles of $\mathrm{K}(\mathrm{M}) \mathrm{FC}-\mathrm{PAN}$ sorption followed by desorption were carried out to establish the sorbent's regeneration capacity.

\subsection{Purification of $\mathrm{Rb}$ from desorbed $\mathrm{KCl}$ solution}

Resorcinol formaldehyde polycondensate resin (RF resin) was used for the purification of $\mathrm{Rb}$ from desorbed $\mathrm{K}(\mathrm{M}) \mathrm{FC}-\mathrm{PAN}$ column solution containing up to $0.2 \mathrm{M} \mathrm{KCl}[18,19]$. For this purpose, $3 \mathrm{~g} \mathrm{RF}$ in $\mathrm{H}^{+}$form was loaded in a glass column (ID: $1.1 \mathrm{~cm}$ ). The bed was conditioned by passing 50 $\mathrm{mL}$ of $1.0 \mathrm{M} \mathrm{KOH}$ solution to convert all the phenolic group $\left(-\mathrm{OH}^{+}\right)$to potassium phenoxide group $\left(\mathrm{O}-\mathrm{K}^{+}\right)$. The desorbed solution containing $\mathrm{Rb}$ and $\mathrm{KCl}$ was passed upward through the $\mathrm{RF}$ column at a low filtration velocity of $2 \mathrm{~m} / \mathrm{h}$. The progress of $\mathrm{Rb}$ loading was monitored by periodic measurement of $\mathrm{Rb}$ in the effluent samples. Finally, purified $\mathrm{Rb}$ was eluted from the resin with $115 \mathrm{ml}$ of $0.1 \mathrm{M} \mathrm{HCl}$ followed by $230 \mathrm{ml}$ of $1.0 \mathrm{M} \mathrm{HCl}$ at a flow rate of $5 \mathrm{~m} / \mathrm{h}$. Lower concentration of $\mathrm{HCl}$ was used in the 

first elution to desorb mainly $\mathrm{K}$ and subsequently a higher concentration was used to desorb the strongly sorbed $\mathrm{Rb}$.

$229 \quad 3 . \quad$ Results and discussion

$230 \quad 3.1 \quad$ Evaluation of Rb sorption by particle form $\mathrm{K}(\mathrm{M}) \mathrm{FC}$

The performance of $\mathrm{K}(\mathrm{M}) \mathrm{FC}$ sorbent for selective Rb sorption capacity was evaluated. The sorption study was carried out with an initial $0.06 \mathrm{mmol} \mathrm{Rb} / \mathrm{L}$ for a viable analysis detection limit.

233 Correspondingly, higher molar ratios of competition ions $(\mathrm{Ca}, \mathrm{K}$, and $\mathrm{Na}$ ) were used, emulating the 234 conditions of SWRO brines.

The chemical stoichiometric composition of $\mathrm{K}(\mathrm{M}) \mathrm{FC}$ was deduced on the basis of one mole of

238 Fe complexion to six moles of cyanide ion $(\mathrm{CN})$. The moles of metal, $\mathrm{M}$ per mole of $\mathrm{K}(\mathrm{M}) \mathrm{FC}$ was 239 calculated by normalising the amount of metal to the amount of Fe [20]. The number of moles of K 240 per $\mathrm{K}(\mathrm{M}) \mathrm{FC}$ mole was calculated by balancing the charges of cations and $\mathrm{CN}$ anion in $\mathrm{K}(\mathrm{M}) \mathrm{FC}$ 241 (electrical neutrality) (Table 2). Similarly, Loos-Neskovic et al. [21] represented K(M)FC with a model structure of $\mathrm{K}_{2 \mathrm{x}} \mathrm{M}_{2-\mathrm{x}}\left[\mathrm{Fe}(\mathrm{CN})_{6}\right]$. A slight excess of $\mathrm{K}$ amount detected in the measured contents compared to the calculated stoichiometric composition was related to the water soluble $\mathrm{K}$ in the pores/channels of $\mathrm{K}(\mathrm{M}) \mathrm{FC}$ as observed in a previous paper [5].

The chemical compositions of the different $\mathrm{K}(\mathrm{M}) \mathrm{FC}$ combinations were relatively similar, with

246 Ni combination having the highest K content (Table 2). A number of K(M)FC studies on Cs sorption 247 relate the major part of the $\mathrm{K}$ content of the sorbent to its sorption capacity due to the exchange 248 between $\mathrm{K}$ and $\mathrm{Cs}$ [22]. This potentially suggests that Rb sorption capacity of the sorbent would be in the order of $\mathrm{KNiFC}>\mathrm{KCuFC}>\mathrm{KCoFC}>\mathrm{KFeFC}$ if all the $\mathrm{K}$ in the structure are exchanged with $\mathrm{Rb}$. 


\subsubsection{Surface potential}

Surface potential of sorbent is an important contributing factor that correlates to the sorbent uptake affinity for ions. An increased negative potential on the sorbent is expected to increase the sorption capacity of positively charged ions such as $\mathrm{Rb}$ by electrostatic adsorption (outer sphere complexation). The surface potential of $\mathrm{K}(\mathrm{M}) \mathrm{FC}$ was investigated with zeta potential analysis in the pH range from 3 to 9 (Fig. 2). KCuFC displayed the highest negative surface potential (-30 to $-32 \mathrm{mV}$ ) at all equilibrium $\mathrm{pH}\left(\mathrm{pH}_{\mathrm{eq}}\right)$ values. Meanwhile for $\mathrm{KCoFC}$ and $\mathrm{KNiFC}$, the highest range of negative surface potential trend was observed around $\mathrm{pH}_{\mathrm{eq}} 7(\mathrm{KCoFC}=-20$ to $-25 \mathrm{mV}$ and $\mathrm{KNiFC}=-10$ to -14 $\mathrm{mV}$ ). The negative surface potential trends suggest that $\mathrm{KCuFC}$ with the highest negative surface potential has the highest potential to electrostatically adsorb the positively charged $\mathrm{Rb}$ and $\mathrm{KNiFC}$ with the lowest negative surface potential has the lowest potential to adsorb Rb. Unlike the other sorbents, KFeFC showed positive surface potential suggesting that the electrostatic sorption of $\mathrm{Rb}$ would be minimal on KFeFC. The positive surface potential of KFeFC could be due the presence of higher positively charged $\mathrm{Fe}^{3+}$ in $\mathrm{KFeFC}$ structure which resulted from the use of $\mathrm{FeCl}_{3}$ to produce this sorbent.

\subsubsection{XRD analysis}

It is a well-established fact that sorption capacity and mechanisms depend on the crystal structure of the sorbent. For this purpose, the X-ray diffraction peaks of the different $\mathrm{K}(\mathrm{M}) \mathrm{FC}$ were analysed as shown in Fig. S1. The different metal K(M)FC's showed a similar general crystal characteristic pattern with three major peaks at $2 \Theta$ positions: $17-18,24-25$, and $35-36$. These peak patterns were consistent with other studies on potassium metal hexacyanoferrate that described the crystal structure to be face-centred cubic $[11,14,21]$. 


\subsubsection{Rb sorption isotherm}

$\mathrm{Rb}$ sorption isotherm was carried out at $\mathrm{pH}_{\mathrm{eq}}$ of $7.0 \pm 0.5$ with the different $\mathrm{K}(\mathrm{M}) \mathrm{FC}$ combinations. The different $\mathrm{K}(\mathrm{M}) \mathrm{FC}$ isotherm data fitted well to both Langmuir and Freundlich models $\left(\mathrm{R}^{2}=0.89\right.$ to 0.98$)$ (Fig. 3 and Table 3$)$. $\mathrm{Rb}$ sorption capacity of the sorbents were in the order of $\mathrm{KCuFC}>\mathrm{KNiFC}>\mathrm{KCoFC}>\mathrm{KFeFC}$. In line with the Rb sorption (mmol/g), a closely similar amount of $\mathrm{K}$ was released $(\mathrm{mmol} / \mathrm{g})$, indicating a stoichiometric electrochemical balance in the exchange process between $\mathrm{Rb}$ and $\mathrm{K}$. The majority of $\mathrm{K}$ release occurred when $\mathrm{Rb}$ exchanged with $\mathrm{K}$ inside the $\mathrm{K}(\mathrm{M}) \mathrm{FC}$ lattice according to $\mathrm{K}_{2}\left[\mathrm{MFe}(\mathrm{CN})_{6}\right]+2 \mathrm{Rb}^{+} \rightarrow \mathrm{Rb}_{2}\left[\mathrm{MFe}(\mathrm{CN})_{6}\right]+2 \mathrm{~K}^{+}[5]$. Naturally, KCuFC with the highest $\mathrm{K}$ release, showed the highest Rb sorption. The results indicated that the accessibility and availability of functional site and surface charge are essential factors in determining $\mathrm{K}(\mathrm{M}) \mathrm{FC}$ capacity [8]. Hence the exchangeable structural $\mathrm{K}$ content as well as the high negative surface charge inferred from the high negative surface potential (Fig. 2) could be the reason for the higher Rb sorptivity of KCuFC (Table 3) compared to the predicted higher sorptivity of KNiFC based on its higher total structural K content (Table 2). Naturally KFeFC with the lowest exchangeable structural $\mathrm{K}$ content and having positive surface potential resulted in the lowest $\mathrm{Rb}$ sorptive capacity. Although the results of this study exhibit that the different metals do play a role in influencing $\mathrm{Rb}$ sorption capacity of $\mathrm{K}(\mathrm{M}) \mathrm{FC}$, more in-depth evaluation need to be carried out to explicitly describe the role of metals here. In line with the high sorptivity of $\mathrm{KCuFC}$ towards $\mathrm{Rb}$, a few studies have highlighted high Cs sorption capacity with $\mathrm{KCuFC}$ compared to other transition metals [8,23]. Based on these results, further studies were conducted with $\mathrm{K}(\mathrm{M}) \mathrm{FC}$ containing $\mathrm{Cu}$ transition metal, $\mathrm{KCuFC}$. 


\subsection{Evaluation of Rb sorption with bead form KCuFC (KCuFC-PAN)}

To overcome the limitation of micro crystalline sorbent application in filter columns, $\mathrm{KCuFC}$ was encapsulated with PAN polymer (Fig. 1), to obtain bead form KCuFC-PAN. In this section, the characterisation and performance of bead form $\mathrm{KCuFC}-\mathrm{PAN}$ for $\mathrm{Rb}$ extraction is presented.

\subsubsection{Surface characteristics of KCuFC-PAN (SEM-EDX)}

The surface and cross sectional SEM images showed the porous and rough morphology appearance of KCuFC-PAN (Fig. 4a). After Rb sorption, no significant morphological changes were observed (Fig. 4b). The EDX revealed the predominant presence of $\mathrm{K}, \mathrm{Fe}$, and $\mathrm{Cu}$ peaks, well representing the elemental constituents of $\mathrm{KCuFC}$ (Fig. 4c) and the EDX element mapping (Fig. 4a \& 4b) established the homogenous distribution of the elements across the bead structure. Upon $\mathrm{Rb}$ sorption, a peak of $\mathrm{Rb}$ was observed in the EDX spectra with a reduction of $\mathrm{K}$ peak intensity, suggesting the sorption of $\mathrm{Rb}$ with the exchange of $\mathrm{K}$ (Fig. 4c). Consistent with this, the $\mathrm{K} / \mathrm{Fe}$ atomic ratio (0.9) of original $\mathrm{KCuFC-PAN} \mathrm{reduced} \mathrm{to} 0.5$ with $\mathrm{Rb}$ sorption. Meanwhile, minimal difference was observed for the $\mathrm{Cu} / \mathrm{Fe}$ atomic ratio between the original and the $\mathrm{Rb}$ sorbed $\mathrm{KCuFC}-\mathrm{PAN}$, suggesting that the $\mathrm{Cu}$ metal was not involved in the $\mathrm{Rb}$ sorption and exchange mechanism.

\subsubsection{XRD analysis of KCuFC-PAN}

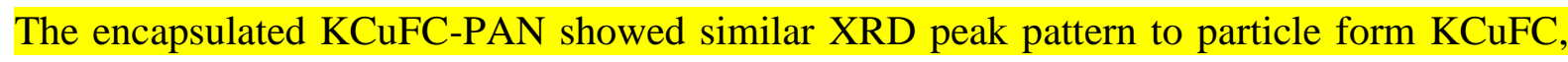
indicating that both KCuFC-PAN and particle form $\mathrm{KCuFC}$ had the same crystal structure (Fig. 5) This established that the encapsulation did not change the crystal structure. Similarly, Nilchi et al. [24] observed matching XRD patterns for $\mathrm{KCoFC}$ in particle and encapsulated forms and concluded that they had the same crystal structure. Du et al. [10] reported on the XRD pattern of KNiFC-PAN, which showed similar peak patterns to KNiFC particle in Fig. S1, validating that the organic polymer encapsulation did not change the crystal structure of the sorbent. 


\subsubsection{Influence of pH on KCuFC-PAN}

Maximum $\mathrm{Rb}$ sorption capacity was achieved at the range of $\mathrm{pH}_{\mathrm{eq}} 6$ to 8 with KCuFC-PAN

(Fig. 6). One reason for the increase in sorption at this $\mathrm{pH}$ range compared to that at lower $\mathrm{pH}$ values

could be related to the increase in electrostatic sorption (outer sphere complexation) resulting from the increased negative zeta potential (Fig. 2) as explained by Naidu et al. [5]. The other reason is that there was competition for $\mathrm{Rb}$ sorption from the high concentration of protons $\left(\mathrm{H}^{+}\right)$at low $\mathrm{pH}$. The high sorption capacity around $\mathrm{pH}$ 6-8 is an advantage in using KCuFC-PAN as a sorbent in removing $\mathrm{Rb}$ from SWRO brine which generally is in this $\mathrm{pH}$ range. All further experiments were carried out at $\mathrm{pH}_{\mathrm{eq}} 7.0 \pm 0.5$.

\subsubsection{Equilibrium isotherm and kinetics of KCuFC-PAN}

The $\mathrm{Rb}$ sorption with KCuFC-PAN fitted very well to Langmuir and Freundlich models $\left(\mathrm{R}^{2}=\right.$ 0.98 and 0.89, respectively) (Fig. 7a). KCuFC-PAN achieved a slightly lower Rb sorption (Langmuir $\mathrm{Q}_{\max }=1.23 \mathrm{mmol} / \mathrm{g}$, ) compared to $\mathrm{KCuFC}$ particles $\left(\right.$ Langmuir $\left.\mathrm{Q}_{\max }=1.68 \mathrm{mmol} / \mathrm{g}\right)($ Table 3) when sorption is expressed per unit weight of the sorbent. The lower Rb sorption with KCuFC-PAN was related to the $30 \%$ additional mass of the inert polymer encapsulation. Upon deduction of the polymer mass, similar sorption capacity was obtained between the KCuFC particles and KCuFC-PAN. Similarly, Moon et al. [17] attributed the lower Cs sorption capacity of PAN nickel potassium hexacyanoferrate $(1.945 \mathrm{mmol} \mathrm{Cs} / \mathrm{g})$ compared to powder form $(2.36 \mathrm{mmol} \mathrm{Cs} / \mathrm{g})$ to the inert polymer mass content.

Rb sorption capacity of $\mathrm{KCuFC}-\mathrm{PAN}$ increased with time, achieving a maximum sorption within $15 \mathrm{~h}(900 \mathrm{~min})\left(\right.$ Fig. 7b). The data fitted well to the PFO model $\left(\mathrm{R}^{2}=0.93\right)$, however the model derived $\mathrm{q}_{\mathrm{e}}=1.38 \mathrm{mmol} / \mathrm{g}$ differed from the experimental $\mathrm{q}_{\mathrm{e}}=0.85 \mathrm{mmol} / \mathrm{g}$. Meanwhile, the PSO model achieved a data fitting with $\mathrm{R}^{2}=0.97$ and $\mathrm{q}_{\mathrm{e}}=0.86 \mathrm{mmol} / \mathrm{g}$, matching very well to the experimental value (Fig. 7b). Therefore the PSO is a better model for use in describing the kinetics of Rb sorption 
by $\mathrm{KCuFC}-\mathrm{PAN}$. In correspondence with $\mathrm{Rb}$ sorption, $\mathrm{K}$ release was detected throughout the entire duration of sorption confirming the Rb sorption mechanism of ion exchange of $\mathrm{Rb}$ with structural $\mathrm{K}$. In contrast, $\mathrm{Cu}$ and $\mathrm{Fe}$ releases were not detected, indicating the mechanical stability of bead form KCuFC-PAN. Rb (1.48 $⿱$ A) diffused into the pore/cavities of the beads containing KCuFC particles and easily displaced $\mathrm{K}(1.33 \AA$ ) from the lattice due to their similar sizes (Table 4) as reported in previous studies $[5,14,25]$. In addition to this mechanism of ion exchange inside the crystal structure, Rb would have also sorbed on the negatively charged surface of $\mathrm{KCuFC}$.

\subsubsection{KCuFC-PAN performance in the presence of SWRO brine ions}

$\mathrm{KCuFC}-\mathrm{PAN}$ performed well as a sorbent for $\mathrm{Rb}$ in the presence of salinity $(0.5$ to $2.5 \mathrm{M} \mathrm{NaCl})$ with only a $12-30 \%$ reduction of $\mathrm{Rb}$ sorption (Fig. 8a). The percentage reduction increased with $\mathrm{NaCl}$ concentration. Other studies have also shown similar trends $[11,26]$. The presence of $\mathrm{Na}$ did not significantly affect the $\mathrm{Rb}$ sorption in spite of the relatively much higher $\mathrm{Na}$ concentration $(10,000$ times and more) than that of $\mathrm{Rb}$. This was associated with the higher hydrated ionic radius of $\mathrm{Na}$ making it less attractive to the sorbent surface [5] and the inability of $\mathrm{Na}$ to exchange with structural $\mathrm{K}$ inside the $\mathrm{KCuFC}$ lattice as $\mathrm{Rb}$ does, which contributes to the selectivity of the sorbent for $\mathrm{Rb}$ (Table 4). Most importantly, these results demonstrated the suitability of KCuFC-PAN application for selective $\mathrm{Rb}$ sorption in highly saline conditions such as SWRO brine.

The presence of other alkali metals, namely $\mathrm{Li}$ and $\mathrm{Cs}$ spiked at molar concentration representing SWRO brine, minimally affected Rb sorption capacity of KCuFC-PAN (Fig. 8b). Only 2-3\% reduction of $\mathrm{Rb}$ sorption $(0.06 \mathrm{mmol} / \mathrm{L})$ was observed in the presence of $\mathrm{Li}$ (molar $\mathrm{Rb}: \mathrm{Li}=1$ : 21). The minimal influence of $\mathrm{Li}$ could be related to its inability to exchange with structural $\mathrm{K}$ and higher hydrated radius $(\mathrm{Li}=3.40-4.70 \AA$ ) that makes the $\mathrm{Li}$ difficult to compete with $\mathrm{Rb}$. Potentially, a significant competition could occur between $\mathrm{Rb}$ and $\mathrm{Cs}$ due to it similar hydrated radius for surface sorption and similar unhydrated radius for exchangeability with structural K [5] (Table 4). However, 
at a significantly low concentration in the $\mathrm{Rb}: \mathrm{Cs}$ molar ratio $=1: 0.001$ (as present in $\mathrm{SWRO}$ brine), $\mathrm{Cs}$ would not affect the sorption of Rb in KCuFC-PAN.

Meanwhile, at a $\mathrm{Rb}: \mathrm{K}$ molar ratio $=1: 7700$, a significant $\mathrm{Rb}$ sorption reduction of $65-70 \%$ was

372 observed (Fig. 8b). Similarly, other studies on Cs sorption have observed stronger competition of K 373 with Cs compared to Na. This was explained to be due to the similar hydrated radius which determines 374 surface sorption and similar unhydrated radius which controls the exchange within the crystal lattice 375 of $\mathrm{K}$ and Cs compared to $\mathrm{Na}$ and $\mathrm{Cs}[26]$. ions having higher charge (divalent) than $\mathrm{Rb}$ (monovalent), due to the larger size of the hydrated $\mathrm{Ca}$ 378 (Table 4) as observed in a number of studies [12,27] and the inability of Ca to exchange with structural $379 \mathrm{~K}$ [5]. However at high Ca concentration, representing the $\mathrm{Rb}: \mathrm{Ca}=1: 14,700$ molarity in SWRO brine, 380 a 15-18\% $\mathrm{Rb}$ sorption reduction was observed. This could be related to non-specific surface sorption 381 where the concentrations of ions determine the competition of ions for sorption [28].

In a simulated SWRO brine solution (containing dominant ions of SWRO brine), a $80-85 \% \mathrm{Rb}$ sorption capacity reduction was observed. Based on the individual solution competition results, the significant sorption capacity reduction in the simulated SWRO brine could be attributed predominantly to the presence of $\mathrm{K}$ and minimally to the other ions. These results reflect that the presence of $\mathrm{K}$ in SWRO brine must be removed to ensure an efficient performance of $\mathrm{KCuFC}$ for $\mathrm{Rb}$ sorption. Alternatively, further sorbent enhancement to increase the capacity of KCuFC-PAN could be carried out. For instance, Lin et al. [29] showed substantially high Cs removal capacity in seawater containing K using modified $\mathrm{KCuFC}$ with mesoporus silica.

390

\subsection{KCuFC-PAN fixed-bed column}

392

\subsubsection{Sorption capacity}


Fig. 9 shows the breakthrough obtained using $5 \mathrm{~g}$ of KCuFC-PAN for the treatment of 0.06 $\mathrm{mmol} / \mathrm{L}$ of $\mathrm{Rb}$ in a column at a flow rate of $2 \mathrm{~m} / \mathrm{h}$. The KCuFC-PAN breakthrough curve is

characterised by (a) a first step where Rb was completely sorbed, (b) a breakthrough upon approaching 4000 BVs (200 h), (c) a gradual increase of the outlet concentration in an S-shaped curve pattern, and (d) a saturation plateau at about $13,400 \mathrm{BVs}(636 \mathrm{~h})$. A sorption capacity of $1.01 \mathrm{mmol} / \mathrm{g}$ was achieved in the column at $100 \%$ breakthrough. A high BV (13,400 BVs) to achieve the column breakthrough established the efficiency of KCuFC-PAN for Rb sorption.

The calculated sorption capacity in the column $(1.01 \mathrm{mmol} / \mathrm{g})$ was mostly similar to the batch Langmuir sorption capacity $\left(\mathrm{Q}_{\max }=1.23 \mathrm{mmol} / \mathrm{g}\right)$ establishing the suitability of $\mathrm{KCuFC}-\mathrm{PAN}$ for column operation. The sorption capacity could be further enhanced by reducing the flow rate as shown by Du et al. [10] as well as by increasing the bed size [30].

\subsubsection{Rb desorption and regeneration of KCuFC-PAN}

\subsubsection{KCuFC-PAN batch desorption}

Different concentrations of $\mathrm{KCl}$ ranging from $0.1 \mathrm{M}$ to $1.0 \mathrm{M}$ were used to desorb $\mathrm{Rb}$ from KCuFC-PAN (Fig. 10). A 70\% desorption was achieved with $0.1 \mathrm{M} \mathrm{KCl}$. From $0.2 \mathrm{M} \mathrm{KCl}$ onwards, it was possible to achieve more than $90 \%$ desorption. Based on these results, $0.2 \mathrm{M} \mathrm{KCl}$ was selected to desorb $\mathrm{Rb}$ from $\mathrm{KCuFC}-\mathrm{PAN}$ in the column.

\subsubsection{KCuFC-PAN column desorption and regeneration}

$\mathrm{Rb}$ was eluted from the $\mathrm{Rb}$-saturated $\mathrm{KCuFC}-\mathrm{PAN}$ sorbent in the column using $0.2 \mathrm{M} \mathrm{KCl}$ at a velocity of $6 \mathrm{~m} / \mathrm{h}$ with $480 \mathrm{BV}$ achieving a $95 \%$ recovery (Table 5). It is important to highlight that KCuFC-PAN retained most of the sorbent material, as such the desorbed solution predominantly contained $\mathrm{Rb}(1.20 \mathrm{mmol} / \mathrm{L})$ and $0.2 \mathrm{M} \mathrm{KCl}$ with traces of $\mathrm{Fe}$ and $\mathrm{Cu}$. These evidently highlights that 
417 the encapsulation of $\mathrm{KCuFC}$ with PAN mitigated the issue of sorbent material losses. Comparatively, 418 our recent study using particle form $\mathrm{KCoFC}$ detected around $0.04 \mathrm{mmol} / \mathrm{L}$ of $\mathrm{Fe}$ and Co from the 419 column effluent with poor regenerative capacity [31]. On the other hand, KCuFC-PAN showed good 420 regeneration capacity. In the second cycle, a sorption capacity of $0.85 \mathrm{mmol} / \mathrm{g}$ was achieved with a $42192 \%$ desorption (Fig. 9 and Table 5). Though the sorption capacity decreased to $0.85 \mathrm{mmol} / \mathrm{g}$ in the second cycle it was still much higher than that of many other sorbents such as several ion exchange resins, zirconium phosphate and ammonium molybdophosphate [1,13].

The XRD analysis showed no structural changes to the regenerated KCuFC-PAN compared to the original KCuFC-PAN (Fig. 5). At the same time, the chemical stoichiometry showed that the regenerated KCuFC-PAN contained similar metal contents to the original KCuFC-PAN (Table 6) supporting the detection of only traces of metal ions in the desorbed solution (Table 5). However, evident reduction of $\mathrm{K}$ contents by $25 \%$ was observed in the regenerated KCuFC-PAN, indicating that the reduction of $\mathrm{K}$ in the regenerated $\mathrm{KCuFC}-\mathrm{PAN}$ contributed to the reduced $\mathrm{Rb}$ sorption capacity in the second column cycle.

The column results are based on complete sorption/desorption up to $\mathrm{C}_{\mathrm{t}} / \mathrm{C}_{0}=1$. In this context, it is worth highlighting that the majority of sorption/desorption in the column occurred within $\mathrm{C}_{\mathrm{t}} / \mathrm{C}_{0}=$ 0.4 to 0.5 . As such, on a practical plant operation, the column could be terminated by $\mathrm{C}_{\mathrm{t}} / \mathrm{C}_{0}=0.4$ to 0.5. Most importantly, the desorbed solution had approximately 20 times concentrated $\mathrm{Rb}$ compared to the influent concentration.

Overall, the two cycles established the good performance capacity of KCuFC-PAN in a column operation and indicated its fairly satisfactory regenerative capacity. Batch studies were conducted with $0.06 \mathrm{mmol} \mathrm{Rb} / \mathrm{L}$ and $\mathrm{KCuFC}$ dose of $0.2 \mathrm{~g} / \mathrm{L}$ for 5 cycles of sorption and desorption $(0.2 \mathrm{M} \mathrm{KCl})$, and the sorption capacity was observed to decrease by up to $30 \%$ (Table S1). In view of the lower sorption capacity in multiple cycles, a further KCuFC-PAN column study with multiple sorption/desorption 
for its reuse.

\subsection{Rb purification using $\mathrm{RF}$ resin}

The $\mathrm{H}^{+}$form $\mathrm{RF}$ resin consists of phenolic hydroxide $(\mathrm{OH})$ group as the functional group. The phenol $\mathrm{OH}$ in the $\mathrm{RF}$ resin was converted to the ionised potassium phenoxide group $\left(\mathrm{O}-\mathrm{K}^{+}\right)$under alkaline condition using $1 \mathrm{M} \mathrm{KOH}$. Rb uptake by $\mathrm{RF}$ resin in the presence of $\mathrm{K}$ is governed by replacing $\mathrm{K}$ in the resin ( $\mathrm{R}$ is the resorcinol formaldehyde polymer) as shown below [32]:

$$
\mathrm{R}-\mathrm{O}-\mathrm{K}^{+}+\mathrm{Rb}^{+}=\mathrm{R}-\mathrm{O}-\mathrm{Rb}^{+}+\mathrm{K}^{+}
$$

The batch study showed that the RF resin was able to achieve a Langmuir maximum Rb sorption capacity of $0.23 \mathrm{mmol} / \mathrm{g}$ (Fig. S2).

The treatment of the desorbed solution $(1.20 \mathrm{mmol} / \mathrm{L} \mathrm{Rb}$ and $0.2 \mathrm{M} \mathrm{KCl})$ was carried out using 454 the RF resin column. The RF resin reached saturation with $\mathrm{Rb}$ and achieved a $\mathrm{Rb}$ sorption capacity of $4550.17 \mathrm{mmol} / \mathrm{g}$ at $83 \mathrm{BV}$ (90 mins) (Fig. 11a). A sequential desorption was carried out at a flow rate of $4565 \mathrm{~m} / \mathrm{h}$ using $0.1 \mathrm{M} \mathrm{HCl}(115 \mathrm{ml})$ on the $\mathrm{Rb}$ saturated $\mathrm{RF}$ to firstly desorb the $\mathrm{K}$ from the resin followed 457 by further desorption with $1.0 \mathrm{M} \mathrm{HCl}(230 \mathrm{ml})$, to desorb $\mathrm{Rb}$, the order of desorption being in 458 accordance with the higher sorption affinity of $\mathrm{Rb}$ than $\mathrm{K}[18,32]$. A 97\% Rb desorption was achieved 459 with a $68 \%$ recovery of the desorbed $\mathrm{Rb}$ in purified form from 60 to100 BV (Fig. 11b).

\section{Conclusions}

462 The following conclusions were obtained from the study:

- $\mathrm{KCuFC}$ showed the highest $\mathrm{Rb}$ sorption (Langmuir maximum sorption, $\mathrm{Q}_{\max }=1.68 \mathrm{mmol} / \mathrm{g}$ ) compared to other metal combinations $\left(\mathrm{KNiFC}, \mathrm{Q}_{\max }=1.43 \mathrm{mmol} / \mathrm{g} ; \mathrm{KCoFC}, \mathrm{Q}_{\max }=1.19\right.$ 
$\mathrm{mmol} / \mathrm{g}$; and $\mathrm{KFeFC}, \mathrm{Q}_{\max }=0.61 \mathrm{mmol} / \mathrm{g}$ ), emerging as the most suitable sorbent among the ones tested to extract $\mathrm{Rb}$. Along with the $\mathrm{Rb}$ sorption, an equal number of mmoles of $\mathrm{K}$ were released, indicating the stoichiometric exchange of $\mathrm{Rb}$ with lattice $\mathrm{K}$ in $\mathrm{K}(\mathrm{M}) \mathrm{FC}$. The higher affinity of $\mathrm{KCuFC}$ towards $\mathrm{Rb}$ sorption was attributed to the higher amounts of $\mathrm{K}$ exchanged from the sorbent crystal lattice and its higher negative surface potential causing greater surface sorption of $\mathrm{Rb}$.

- KCuFC was successfully encapsulated with an organic polymer (PAN), producing $\mathrm{KCuFC}-$ PAN beads (Langmuir $\mathrm{Q}_{\max }$ for $\mathrm{Rb}$ of $1.23 \mathrm{mmol} / \mathrm{g} \mathrm{KCuFC}$ ). Rb sorption capacity by $\mathrm{KCuFC}$ for $\mathrm{Rb}$ extraction from saline conditions such as SWRO brine. However, the presence of $\mathrm{K}$ in SWRO brine resulted in $65-70 \%$ reduction of $\mathrm{Rb}$ sorption, reflecting the need to further address the challenge of efficiently extracting $\mathrm{Rb}$ from complex matrices such as $\mathrm{SWRO}$ brine

- In a fixed-bed column condition, KCuFC-PAN achieved a Rb sorption capacity of 1.01 $\mathrm{mmol} / \mathrm{g}$, (closely similar to the batch study) and $95 \%$ desorption of sorbed $\mathrm{Rb}$ with $0.2 \mathrm{M} \mathrm{KCl}$. The sorption capacity reduced only by $16 \%$ in the second cycle of Rb sorption/desorption, establishing the suitability of KCuFC-PAN for column operation and its regenerative capacity of KCuFC-PAN.

- $\mathrm{Rb}$ was selectively separated from $\mathrm{K}$ in the desorbed solution, using $\mathrm{RF}$ resin in a fixed-bed column and a sequential $\mathrm{HCl}$ desorption, producing $68 \%$ of purified $\mathrm{Rb}$.

- The approach of Rb sorption with KCuFC-PAN and purification with RF resin demonstrated in this study provides useful information for its potential application in extracting $\mathrm{Rb}$ from SWRO brine. Nevertheless, a number of factors must be still evaluated for a full practical implementation of $\mathrm{Rb}$ sorption from SWRO brine. In light of this, technology integration such as membrane distillation to increase the Rb concentration in SWRO brine prior to sorption 

brine.

492 Acknowledgement

493 This work was funded by Australian Research Council Discovery Research Grant (DP150101377).

494

495

496

497

498

499

500

501

502

503

504

505 
507 [1] M. Petersková, C. Valderrama, O. Gibert, J.L. Cortina, Extraction of valuable metal ions (Cs, 508

[2] J. Jandova, P. Dvořák, J. Formánek, H.N. Vu, Recovery of rubidium and potassium alums from

[4] A. Clearfield, Inorganic ion exchangers, past, present, and future, Solvent Extr. Ion Exch. 18 (2000) 655-678.

[5] G. Naidu, T. Nur, P. Loganathan, J. Kandasamy, S. Vigneswaran, Selective sorption of rubidium by potassium cobalt hexacyanoferrate, Sep. Purif. Technol. 163 (2016) 238-246.

[6] P.A. Haas, A review of information on ferrocyanide solids for removal of cesium from solutions, Sep. Sci. Technol. 28 (1993) 2479-2506.

[7] C. Loos-Neskovic, M. Fedoroff, Fixation mechanisms of cesium on nickel and zinc ferrocyanides, Solvent Extr. Ion Exch. 7 (1989) 131-158.

[8] M. Ramaswamy, Sorption of cesium by hexacyanoferrate composites from neutral and acidic media, Solvent Extr. Ion Exch. 15 (1997) 1119-1131.

[9] J. Lehto, R. Harjula, J. Wallace, Absorption of cesium on potassium cobalt hexacyanoferrate (II), J. Radioanal. Nucl. Chem. 111 (1987) 297-304.

[10] Z. Du, M. Jia, X. Wang, Cesium removal from solution using PAN-based potassium nickel hexacyanoferrate (II) composite spheres, J. Radioanal. Nucl. Chem. 298 (2013) 167-177. 
530 [11] C. Vincent, A. Hertz, T. Vincent, Y. Barré, E. Guibal, Immobilization of inorganic ion-exchanger into biopolymer foams-Application to cesium sorption, Chem. Eng. J. 236 (2014) 202-211.

[12] L. Vrtoch, M. Pipíška, M. Horník, J. Augustín, J. Lesný, Sorption of cesium from water solutions on potassium nickel hexacyanoferrate-modified Agaricus bisporus mushroom biomass, J. Radioanal. Nucl. Chem. 287 (2011) 853-862.

[13] P. Krys, F. Testa, A. Trochimczuk, C. Pin, J. Taulemesse, T. Vincent, E. Guibal, Encapsulation of ammonium molybdophosphate and zirconium phosphate in alginate matrix for the sorption of rubidium (I), J. Colloid Interface Sci. 409 (2013) 141-150.

[14] A.K. Vipin, B. Hu, B. Fugetsu, Prussian blue caged in alginate/calcium beads as adsorbents for removal of cesium ions from contaminated water, J. Hazard. Mater. 258 (2013) 93-101.

[15] F. Han, G. Zhang, P. Gu, Adsorption kinetics and equilibrium modeling of cesium on copper ferrocyanide, J. Radioanal. Nucl. Chem. 295 (2013) 369-377.

[16] Y. Qing, J. Li, B. Kang, S. Chang, Y. Dai, Q. Long, C. Yuan, Selective sorption mechanism of Cs on potassium nickel hexacyanoferrate (II) compounds, J. Radioanal. Nucl. Chem. 304 (2015) 527-533.

[17] J. Moon, K. Kim, C. Jung, Y. Shul, E. Lee, Preparation of organic-inorganic composite adsorbent beads for removal of radionuclides and heavy metal ions, J. Radioanal. Nucl. Chem. 246 (2000) 299-307.

[18] S. Samanta, M. Ramaswamy, B. Misra, Studies on cesium uptake by phenolic resins, Sep. Sci. Technol. 27 (1992) 255-267.

[19] V. Gorshkov, V. Ivanov, I. Staina, Selectivity of phenol-formaldehyde resins and separation of rare alkali metals, React. Funct. Polym. 38 (1998) 157-176. 
553 [20] H. Mimura, M. Kimura, K. Akiba, Y. Onodera, Selective removal of cesium from sodium nitrate solutions by potassium nickel hexacyanoferrate-loaded chabazites, Sep. Sci. Technol. 34 (1999) 17-28.

[21] C. Loos-Neskovic, M. Fedoroff, E. Garnier, P. Gravereau, Zinc and nickel ferrocyanides: preparation, composition and structure, Talanta 31 (1984) 1133-1147.

[22] J. Lehto, R. Paajanen, R. Harjula, Selectivity of potassium cobalt hexacyanoferrate (II) for alkali and alkaline earth metal ions, J. Radioanal. Nucl. Chem. 164 (1992) 39-46.

[23] V. Avramenko, S. Bratskaya, V. Zheleznov, I. Sheveleva, O. Voitenko, V. Sergienko, Colloid stable sorbents for cesium removal: preparation and application of latex particles functionalized with transition metals ferrocyanides, J. Hazard. Mater. 186 (2011) 1343-1350.

[24] A. Nilchi, A. Khanchi, H. Atashi, A. Bagheri, L. Nematollahi, The application and properties of composite sorbents of inorganic ion exchangers and polyacrylonitrile binding matrix, $\mathrm{J}$. Hazard. Mater. 137 (2006) 1271-1276.

[25] C. Loos-Neskovic, S. Ayrault, V. Badillo, B. Jimenez, E. Garnier, M. Fedoroff, et al., Structure of copper-potassium hexacyanoferrate (II) and sorption mechanisms of cesium, J. Solid State Chem. 177 (2004) 1817-1828.

[26] J. Orechovska, P. Rajec, Sorption of cesium on composite sorbents based on nickel ferrocyanide, J. Radioanal. Nucl. Chem. 242 (1999) 387-390.

[27] S. Ayrault, C. Loss-Neskovic, M. Fedoroff, E. Garnier, Copper hexacyanoferrates: preparation, composition and structure, Talanta 41 (1994) 1435-1452.

[28] C. Dwivedi, S.K. Pathak, M. Kumar, S.C. Tripathi, P.N. Bajaj, Potassium cobalthexacyanoferrate-gel beads for cesium removal: kinetics and sorption studies, RSC Adv. 3 (2013) 22102-22110.

[29] Y. Lin, G.E. Fryxell, H. Wu, M. Engelhard, Selective sorption of cesium using self-assembled monolayers on mesoporous supports, Environ. Sci. Technol. 35 (2001) 3962-3966. 
579 [30] A.M. El-Kamash, Evaluation of zeolite A for the sorptive removal of $\mathrm{Cs}^{+}$and $\mathrm{Sr}^{2+}$ ions from aqueous solutions using batch and fixed bed column operations, J. Hazard. Mater. 151 (2008) $432-445$.

582 [31] T. Nur, G. Naidu, P. Loganathan, J. Kandasamy, S. Vigneswaran, Rubidium recovery using 583 potassium cobalt hexacyanoferrate sorbent, Desalin. Water Treat. (2016) 1-9.

584 [32] D. Banerjee, M.A. Rao, P. Wattal, Separation and recovery of Cs from high active waste 585 simulant using resorcinol formaldehyde polycondensate resin: batch and column studies, Sep. Sci. Technol. 48 (2013) 133-139. 